\title{
ANGINA DE LUDWIG: REPORTE DE UN CASO EN TOLIMA, COLOMBIA
}

\section{LUDWIG'S ANGINA: CASE REPORT IN TOLIMA, COLOMBIA}

Quintero Margareth Karem Gheraldine ${ }^{1}$, Villalobos, Santiago ${ }^{2}$.

\section{RESUMEN}

La angina de Ludwig es una patología de origen infecciosa que afecta principalmente el suelo de la boca, avanzando hacia los espacios submandibulares, sublinguales y submentonianos, progresando hacia la vía aérea, pudiendo causar su colapso, falla ventilatoria y muerte. Se realiza una revisión corta actual de la más reciente literatura acerca de esta patología. Se presenta paciente femenina adulta mayor que ingresa al servicio de urgencias con diagnóstico de celulitis en región facial. Es valorada por el médico internista de turno, quien rápidamente diagnostica la Angina de Ludwig, instaura tratamiento antibiótico de amplio espectro e interconsulta con cirugía general por posible falla ventiladora con vía aérea de difícil acceso. Gracias al rápido y oportuno diagnóstico se instauró el manejo adecuado y fue posible contener la patología sin complicaciones graves.

\section{ABSTRACT}

Ludwig's Angina is an infectious disease that affects mainly the floor of the mouth, progressing through submandibular, sublingual and submentonian spaces, making its way to the airway, being able to cause its collapse, thus causing ventilatory failure and death. First of all, we begin with a short review of the latest literature regarding this illness. It's presented an elderly female adult, who is brought into the emergency service with a face cellulitis diagnose. She is examined by the internist specialist on shift, who rapidly diagnoses Ludwig's Angina, establishes broad spectrum antibiotic treatment and interconsults with the general surgery service due to possible ventilatory failure with and a hard to access air way. Thanks to the rapid and timely diagnose an adequate treatment is established and it is possible to contain this pathology without grave complications.

\section{INTRODUCCIÓN}

T a angina de Ludwig o flemón difuso Whiperséptico y gangrenoso de piso de boca, es una patología de tejidos blandos, rara y progresiva, descrita principalmente en niños, a menudo de origen odontogénico (40-60\%). Sin embargo, se ha relacionado también con fractura de mandíbula abierta, sialoadenitis de la glándula submaxilar, laceraciones de tejidos blandos orales, heridas en piso de boca e infecciones orales secundarias. Se caracteriza por celulitis de los espacios submentonianos, submandibular y sublingual que representa una urgencia en cirugía Bucal y Maxilofacial por su evolución rápida a gangrena y diseminación que compromete estructuras vitales de la región cervical desencadenando alto riesgo vital debido a la obstrucción de la vía aérea provocando asfixia y muerte o en algunos casos, obliteración o ruptura de grandes vasos y mediastinitis, entre $\operatorname{otros}^{1,2,3,4}$.

En dicha infección se pueden encontrar bacterias aerobias $y$ anaerobias gram positivas como gram negativas, Herpes virus, parásitos y hongos, encontrándose principalmente un origen polimicrobiano (50-80\%), siendo los principales agentes (Streptococcus viridans, Streptococcus salivarious, Streptococcus periodontitis), Staphylococcus aureus, Fusobacterium nucleatum, Actynomices y Candida albicans, los cuales, a través del borde posterior de la línea y músculo milohioideo alcanzan los espacios submaxilar (sublingual-submilohioideo) y submentoniano ${ }^{3,5}$. Así mismo, se debe tener en cuenta que esta entidad puede estar asociada a comorbilidades tales como la diabetes mellitus, hipertensión arterial, anemia, obesidad, asma, enfermedad tiroidea, Virus de la Inmunodeficiencia Humana (VIH), entre otros, por lo que es trascendental identificar la clínica para realizar el diagnóstico oportuno e iniciar rápidamente antibioticoterapia intravenosa para evitar la muerte ${ }^{6,7}$. Esta entidad infrecuente pero trascendental, requiere alta sospecha médica y conceptos claros clínicamente para realizar un abordaje integral y temprano para evitar así complicaciones mortales. Por este motivo, se decide exponer el siguiente caso clínico diagnosticado en un hospital de segundo nivel en Colombia.
1,2Estudiantes de último año. Facultad Ciencias de la Salud. Programa de Medicina. Universidad del Tolima (Ibagué, Tolima, Colombia).

Correspondencia a: Santiago Villalobos Guarin santivillagua@gmail.com

Palabras clave: Angina de Ludwig, adulto mayor, diabetes mellitus, macroglosia.

Keywords: Ludwig 's Angina, elderly adult, diabetes mellitus, macroglossia.

Procedencia y arbitraje: no comisionado, sometido a arbitraje externo.

Recibido para publicación 1 de mayo de 2019 Aceptado para publicación: 17 de noviembre de 2019

Citar como:

Quintero K, Villalobos S. Angina de ludwing:reporte de un caso en Tolima, Colombia. Rev Cient Cienc Med. 2019; 22(2): 53-57 


\section{PRESENTACIÓN DEL CASO}

Se trata de una paciente femenina de 62 años de edad con antecedente médico de diabetes mellitus tipo 2 insulinorequirente de más de 20 años de evolución, asociado a polineuropatía y retinopatía diabética, que ingresa por cuadro clínico de aproximadamente 8 días de evolución caracterizado por aparición de lesiones maculares blanquecinas en lengua, paladar y encías asociado a macroglosia, deterioro de la fonación y signos inflamatorios en región mandibular y cervical en zona I, II y III con eritema que compromete hasta región torácica, se automedica durante 3 días con nistatina en suspensión oral $6 \mathrm{cc}$ mantenida en la boca cada 6 horas sin presentar mejoría de la sintomatología, motivo por el que acude a servicio de urgencias.

En el examen físico, se encuentra normotensa, taquicardica, febril, adecuados índices de saturación, sin signos de dificultad respiratoria ni deterioro neurológico con marcada limitación en la fonación. Se observa aumento severo del volumen con predominio de la región submentoniana y submandibular bilateral, apertura bucal limitada de $2,5 \mathrm{~cm}$ y labios eritematosos con pérdida de tejido superficial (ver Figura 1), adenomegalias cervicales dolorosas en región anterior y submandibular de $2 \mathrm{~cm}$. En el examen intrabucal se evidencia ausencia de varias piezas dentarias, halitosis, aumento severo del volumen del piso de la boca y espacio sublingual bilateral, sialorrea abundante, necrosis en cara lateral derecha y placas purulentas en cara lateral izquierda de la mandíbula con macroglosia que obstruye visualización de orofaringe (ver Figura 2).

Dado las características clínicas se sospecha de Angina de Ludwig, por lo que es trasladada a sala de reanimación, se inicia fluidoterapia y antibioticoterapia endovenosa terapéutica con Piperacilina Tazobactam 4,5g cada 6 horas y Clindamicina $600 \mathrm{mg}$ cada 6 horas intravenoso, manejo antiinflamatorio con diclofenaco $75 \mathrm{mg}$ cada 12 horas intravenoso, insulinoterapia de base con $32 \mathrm{UI}$ de Insulina Glargina en la mañana y $12 \mathrm{UI}$ en la noche y tromboprofilaxis con enoxaparina $40 \mathrm{mg}$ subcutáneos diarios.

Se solicitan paraclínicos, los cuales reportan hemograma con neutrofilia aislada y trombocitopenia moderada, tiempos de coagulación prolongados, química sanguínea con hiperglicemia y resto dentro de límites normales.

Se indica tomografía computarizada en la que se evidencia cambios de aspecto inflamatorio del piso de la boca y la región submandibular con extensión a las glándulas submandibulares y adenomegalias bilaterales de aspecto reactivo con disminución leve del lumen de la vía aérea a nivel cervical, confirmando el diagnóstico (ver Figura 3 y 4 ).

Se continúa terapéutica establecida y se inicia trámite de remisión a unidad de cuidados intermedios donde prolongan manejo médico instaurado con posterior mejoría de signos inflamatorios locales y resolución clínica.

\section{DISCUSIÓN}

Karl Friedrich Wilhelm von Ludwig describió en 1836 la angina de Ludwig, actualmente se conoce que es una entidad infrecuente y poco conocida que afecta desde niños hasta ancianos, indistintamente del género, aunque en pocos reportes se ha descrito de una manera levemente superior en mujeres; siendo una de las complicaciones más importantes de las infecciones odontogénicas que suelen relacionarse con la diabetes mellitus como comorbilidad, por

Figura 1: Vista frontal. Se observa aumento severo del volumen de la región submentoniana y submandibular.

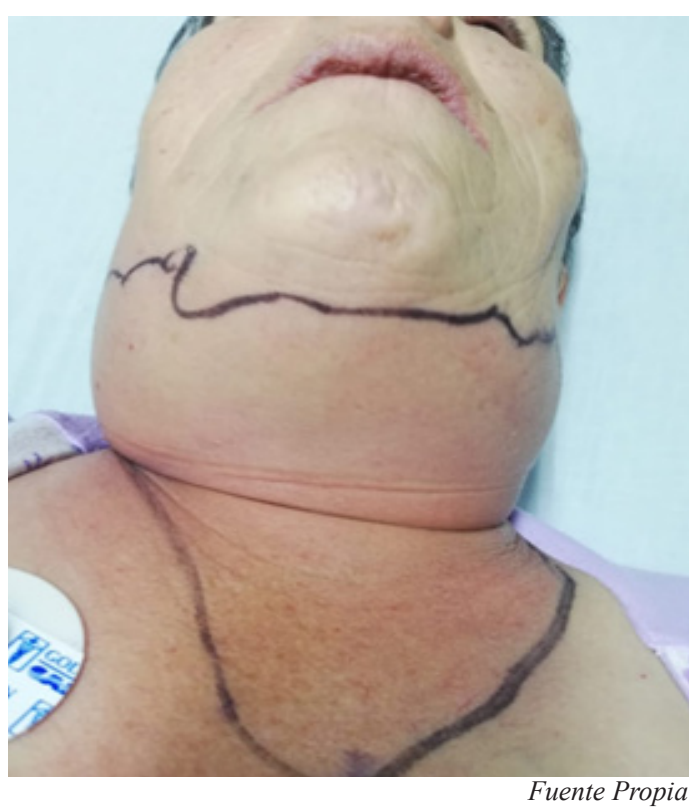

Figura 2: Vista frontal. Se observa macroglosia marcada que obstruye visualización de orofaringe, además de placas blanquecinas y eritema en lengua.

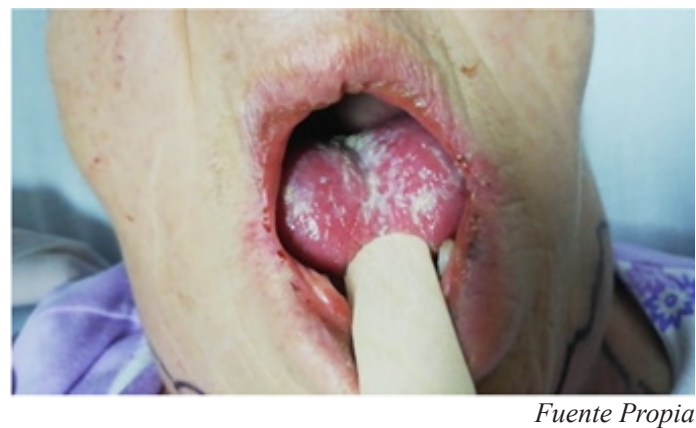

Fuente Propia

Rev Cient Cienc Méd Volumen 22, No $2: 2019$ 
lo que resulta importante en estos pacientes la realización de tratamientos odontológicos preventivos. Igualmente, también influye el inadecuado tratamiento de un foco infeccioso simple que evoluciona rápidamente a un foco complejo, se evidencia principalmente en aquellos pacientes que se automedican, factor que sobreagregado a la diabetes incrementa la mortalidad ante la falta de tratamiento oportuno $0^{9,10}$.

La prevalencia de las infecciones del piso de la boca varía entre el 4 y $17 \%$, estando las infecciones odontogénicas como causa principal entre un 52 y $97 \%$, con un cuadro clínico de presentación común, dado por fiebre, macroglosia y disfagia, que posteriormente se acompaña de edema. La dificultad respiratoria se presenta en estadios avanzados cuando ha progresado la inflamación secundaria a la infección local. La evaluación de la extensión topográfica de la infección se realiza por medio de la TAC, la cual se considera el gold estándar en infecciones profundas cervicales ${ }^{11}$.

El tratamiento de esta entidad incluye el manejo de la vía aérea y antibioticoterapia intensiva para alcanzar la eliminación del patógeno, pudiendo ser necesario el desbridamiento de la superficie radicular y extracción del diente infectado para controlar el foco principal. En cuanto a la terapia antibiótica, los inhibidores de betalactamasas presentan buenos resultados terapéuticos al igual que la clindamicina asociado a otros antibióticos. De la misma manera, lo principal que se debe tener en cuenta en estos pacientes es el manejo de la vía aérea, quienes en algunos casos requieren traqueostomía, práctica que ha venido disminuyendo por la aparición de

Figura 3: Corte coronal. Se evidencia inflamación del piso de la boca y región submandibular.

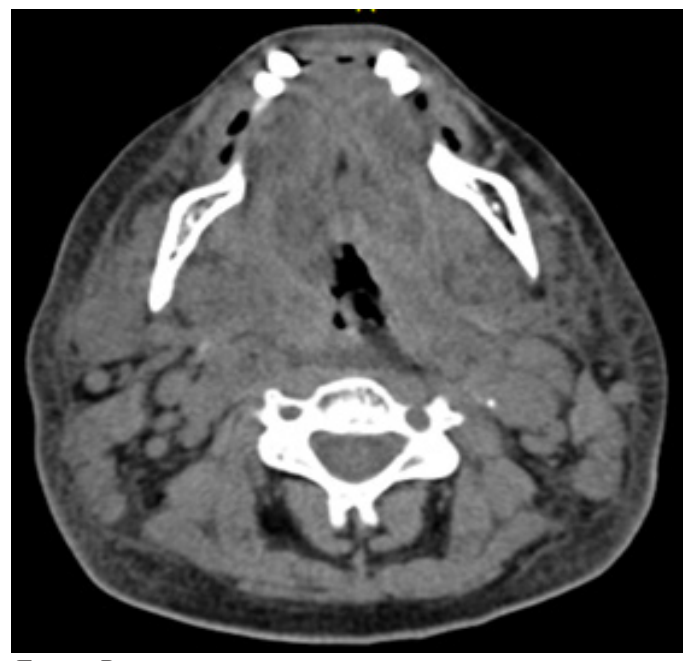

Fuente Propia nuevas técnicas como la intubación retrógrada o por fibra óptica ${ }^{12}$, para ello se debe tener conocimientos claros para la identificación de las vías aéreas difíciles, en este caso no anticipadas, por lo que se debe indagar por antecedentes y un examen físico para evitar consecuencias que pongan en riesgo la vida del paciente, contando actualmente con otras herramientas disponibles aparte de la laringoscopía convencional como lo son los videolaringoscopios dirigidos, laringoscopios de fibra óptica indirecta, entre otros. En el caso de la Angina de Ludwig la intubación con fibra óptica, despierta bajo anestesia tópica ha demostrado ser un método menos invasivo para asegurar la vía aérea en pacientes con infección profunda del cuello ${ }^{8}$, teniendo en cuenta que la intubación con laringoscopía directa podría causar un colapso agudo de la vía aérea, surgiendo como opción la traqueostomía en el caso de que no fuera posible la intubación con fibra óptica o por la presencia de intentos de intubación fallidos ${ }^{13}$.

Sin embargo, es trascendental determinar los predictores de intubación difícil antes de optar por la técnica de intubación por medio de la escala de Mallampati, escala Patil-Aldreti (distancia tiromentoniana), distancia esternomentoniana y la clasificación de Cormarck-Lehane con el fin de conocer la situación a la que se enfrenta el clínico e incrementar la seguridad de la vía aérea ${ }^{14}$.

En nuestro caso, no fue necesario la realización de medidas invasivas en la vía aérea gracias al diagnóstico y manejo temprano que permitió la modulación de la respuesta inflamatoria local así como la extensión

Figura 4: Vista sagital. Se evidencia macroglosia con aumento del volumen de la región submentoniana y submandibular con disminución leve del lumen de la vía aérea cervical compatible con los hallazgos al examen fisico

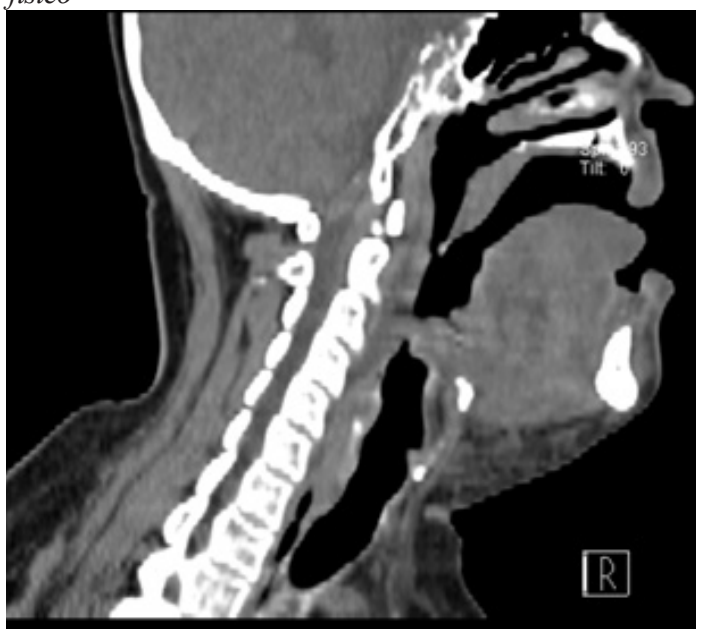

Fuente Propia

Angina de Ludwig 
Cuadro 1. A continuación se relacionan los diagnósticos diferenciales tenidos en cuenta luego de realizar la anamnesis y examen físico, así como las características clínicas de cada una de las entidades y las razones que se encontraron en contra de ellas.

\begin{tabular}{|c|c|c|}
\hline $\begin{array}{l}\text { Diagnósticos } \\
\text { diferenciales }\end{array}$ & $\begin{array}{l}\text { Características } \\
\text { clínicas }\end{array}$ & Contra \\
\hline $\begin{array}{l}\text { Reacción alérgica } \\
\text { asociada a } \\
\text { medicamentos } \\
\text { (Nistatina) }\end{array}$ & $\begin{array}{l}\text { Rash, urticaria, } \\
\text { síndrome de } \\
\text { Stevens-Johnson, } \\
\text { angioedema }^{15} \text {. }\end{array}$ & $\begin{array}{l}\text { Paciente que en algún momento de su vida se automedicó con } \\
\text { nistatina sin ningún efecto secundario. } \\
\text { Rash, urticaria y síndrome de Stevens-Johnson: No presentaba } \\
\text { erupción cutánea ni alteraciones de otras zonas de la piel, } \\
\text { mucosas y ojos }{ }^{15} \text {. } \\
\text { Angioedema por bradiquininas: Se ha registrado principalmente por } \\
\text { los inhibidores de la enzima convertidora de angiotensina (IECA) } \\
\text { al bloquear la cinasa II, enzima encargada de la degradación de la } \\
\text { bradiquinina }{ }^{15} \text {. } \\
\text { Angioedema por alergia: Aparece de minutos a } 1 \text { hora después de } \\
\text { administrado el medicamento, se relaciona con urticaria }{ }^{15} \text {. }\end{array}$ \\
\hline $\begin{array}{l}\text { Enfermedades } \\
\text { periodontales } \\
\text { necrosantes }\end{array}$ & $\begin{array}{l}\text { Infección de las } \\
\text { encías con úlceras } \\
\text { dolorosas en las } \\
\text { papilas interdentales } \\
\text { que afecta } \\
\text { estructuras fijadoras } \\
\text { del diente y afecta } \\
\text { planos profundos } \\
\text { debajo de la línea } \\
\text { mucogingival }{ }^{16} \text {. }\end{array}$ & $\begin{array}{l}\text { Respeta línea mucogingival y el tejido profundo afectado es de } \\
\text { gran extensión y no concordante con el área de inflamación } \\
\text { gingival. } \\
\text { Baja prevalencia y se asocia a } \mathrm{VIH}^{16} \text {. }\end{array}$ \\
\hline $\begin{array}{l}\text { Celulitis } \\
\text { odontogénica }\end{array}$ & $\begin{array}{l}\text { Infección de } \\
\text { los espacios } \\
\text { cervicofaciales } \\
\text { por extensión } \\
\text { de un absceso } \\
\text { odontogénico }{ }^{16} \text {. }\end{array}$ & $\begin{array}{l}\text { Al examen físico no se evidencia presencia de abscesos } \\
\text { odontogénicos. }\end{array}$ \\
\hline $\begin{array}{l}\text { Fascitis } \\
\text { necrozante }\end{array}$ & $\begin{array}{l}\text { Infección secundaria } \\
\text { a pérdida de barrera } \\
\text { de la piel que permite } \\
\text { que penetre el agente } \\
\text { causal a planos } \\
\text { profundos }^{17} \text {. }\end{array}$ & $\begin{array}{l}\text { Paciente no presentó trama ni cirugía previa que permitiera entrada } \\
\text { de microbio. Además, suele aparecer en extremidades. } \\
\text { Los bordes del eritema son delimitados sin hiperalgesia. Al ingreso } \\
\text { no presentaba flictenas ni ampollas, no habían crepitos ni ulceras, } \\
\text { además tampoco fueron documentados durante la hospitalización. } \\
\text { No hubo evidencia de toxicidad sistémica clínica ni paraclínica. } \\
\text { Score LRINEC para riesgo bajo ( } 3 \text { puntos). } \\
\text { Tomografía axial computarizada sin evidencia de gas en tejidos }_{\text {blandos }^{17} \text {. }}\end{array}$ \\
\hline
\end{tabular}

de la infección, promoviendo la disminución de la obstrucción inicial de la vía aérea, debido a que el diagnóstico y manejo temprano de la Angina de Ludwig es la piedra angular para prevenir la falla ventilatoria y muerte.

En muchas ocasiones, el hecho de no tener un conocimiento más amplio acerca del gran espectro de enfermedades y patologías que existen hoy en día limita a usar diagnósticos convencionales y a veces tratamientos que se quedan cortos, generando falencias y errores en el manejo de los pacientes que sin duda tienen efecto en el sistema de salud. Por esto, el personal de salud debe mantenerse actualizando y ampliando su conocimiento.

La Angina de Ludwig es una patología potencialmente mortal que puede afectar a cualquier grupo de edad y género, siendo la mejor estrategia el diagnóstico y manejo temprano basado en el mantenimiento de la vía aérea y la antibioticoterapia de amplio espectro para evitar la falla ventilatoria $y$ muerte. 
1. Jimenez SJ, Galvis MD, Britto MI. Presentación de caso angina de ludwing. Presentación de caso clínico. Rev Cub Med Int Emerg [Internet]. 2008 [Citado en Abril 2019]; 7(3):8. Disponible en: http:// bvs.sld.cu/revistas/mie/vol7_3_08/mie03308.pdf

2. Re Cecconi D, Fornara R. Ludwig's angina: a case report with a 5-year follow-up. G Ital Endod [Internet]. 2018 [Citado en Abril 2019];32(2):70-5. Disponible en: https://linkinghub.elsevier.com/retrieve/ pii/S1121417118300451

3. Pereira R, Goulart D. Angina De Ludwig Com Mediastinite: Relato De Caso. Rev UNINGA [Internet]. 2018 [Citado en Abril 2019]/;55(S1):736. Disponible en: http://revista.uninga.br/index.php/ uninga/article/view/2663/1749

4. Gagliardi AF, Contreras MG, Gudiño RA, Zeballos RJ. Angina de Ludwig. Reporte de 2 casos. Rev Esp Cir Oral Maxilofac [Internet]. 2014 [Citado en Abril 2019];36(4):149-204. Disponible en: https://www. elsevier.es/es-revista-revista-espanola-cirugia-oralmaxilofacial-300-articulo-angina-ludwig-reporte-2casos-S1130055812001499

5. Deidán CR, Pacheco-Ojeda L, Narvaez M, Quisiguiña $\mathrm{K}$. Angina de Ludwig. Experiencia en 29 pacientes. Ac. Otorrino Cirg de Cab y Cue [Internet]. 2013 [Citado en abril 2019];41(1):19-24. Disponible en: http://revista. acorl.org/index.php/acorl/article/view/162/114

6. An J, Singhal M. Ludwig Angina. StatPearls [Internet]. 2019 [Citado en abril 2019]. Dsiponible en: http://www.ncbi.nlm.nih.gov/pubmed/29493976

7. Botha A, Jacobs F, Postma C. Retrospective analysis of etiology and comorbid diseases associated with Ludwig's Angina. Ann Maxillofac Surg. [Internet]. 2015 [Citado en abril 2019];5(2):168-73. Disponible en: http://www.amsjournal.com/article.asp?issn=22310746; year $=2015$; volume $=5$; issue $=2 ;$ spage $=168$; epage $=17$ 3 ; aulast $=$ Botha

8. Hariharasudhan B, Mane R, Gogate VA, Dhorigol MG. Successful management of difficult airway: A case series. Jour Sci Soc Internet]. 2016 [Citado en abril 2019];43(3):151-4. Disponible en: http://www. jscisociety.com/article. asp? issn $=0974-5009$; year $=2016 ; v$ olume $=43 ;$ issue $=3 ;$ spage $=151$; epage $=154$; aulast $=$ Hariha rasudhan
9. Camargos F, Cosrtes H, Guimaraes de Aguiar E, Neves E, Ribeiro da Gloria J, Sette Dias A. Severe odontogenic infection and its epidemiological profile. Rev. Cir. Traumatol. Buco-maxilo-fac [Internet]. 2016 [Citado en abril 2019];16(2):25-30. Disponible en: http:// revodonto.bvsalud.org/scielo.php?script=sci arttexterpid $=$ S1808-52102016000200005

10. Garces S, Maldonado D. Estudio retrospectivo sobre la incidencia de las infecciones cérvico faciales en hospital pablo arturo suárez en el período comprendido entre enero del 2008 y diciembre del 2010. Odontol [Internet]. 2015 [Citado en abril 2019];17(1):15-22. Disponible en:https://dialnet. unirioja.es/servlet/articulo?codigo $=5597283$

11. Deidan C, Ojjeda L, Black M, Quisiguia K. Angina de Ludwig. Expieriencia en 29 pacientes. ACORL [Internet]. [Citado en abril 2019];41(1):19-24.

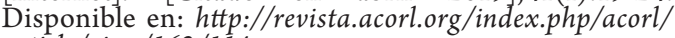
article/view/162/114

12. Young C, Fong K. Editorial case report Ludwig Angina - The longest distance in this planet. Adv Emer Medic. 2018 [Citado en abril 2019]. Disponible en: http://aem.usp-pl.com/index.php/aem/article/ view $/ 135 / 13$

13. Shih C, Wang J, Chen S, Hsi Y. Focused ultrasound assists in diagnosis and management of difficult airway in Ludwig's angina. J Med Ultras [Internet]. 2019[Citado en abril 2019]. Disponible en: http://www. jmuonline.org/preprintarticle. asp? id $=249638$

14. Holguín L, Vásquez L, Cardona R. Angioedema. Rev Alerg Mex [Internet]. 2016 [Citado en abril 2019];63(4):373-84. Disponible en:revistaalergia.mx/ ojs/index.php/ram/article/download/220/362

15. Robles P, Javierre A, Moreno N, Mas Casals A, Frutos E, Morato L. Manejo de las infecciones ontogénicas en las consultas de atención primaria: ¿antibiótico? Rev Aten Prim [Internet]. 2017 [Citado en abril 2019];49(10):565-624. Disponible en:https://www.elsevier.es/es-revista-atencion-primaria27-articulo-manejo-las-infecciones-odontogenicaslas-S0212656717301348

16. Ferrer Y, Morejón Y. Fascitis necrosante. Actualización del tema. Medisur [Internet]. 2018 [Citado en abril 2019];16(6):920-9. Disponible en:http://www.medisur.sld.cu/index.php/medisur/ article/view/3855/2690 